\title{
DIREITOS SOCIAIS E POLÍTICAS PÚBLICAS EXTRAFISCAIS: A DESONERAÇÃO FISCAL COMO INSTRUMENTO DE EFETIVAÇÃO DA IGUALDADE MATERIAL E PROTEÇÃO À DIGNIDADE HUMANA
}

\section{Darlan Alves Moulin*}

\section{RESUMO}

O presente artigo visa analisar a importância da concretização dos direitos sociais para a efetivação da igualdade material e o papel das políticas públicas extrafiscais, no viés da desoneração fiscal, para a concretização de tais direitos. Será analisado, ainda, se a tributação no Brasil tem sido utilizada para a promoção do Estado e Bem-Estar Social, com a efetivação dos Direitos Sociais ou se ela é meramente arrecadatória. Para tanto, utilizou-se dos métodos crítico, de revisão bibliográfica e análise documental para alcançar tais objetivos.

Palavras-chave: Direitos sociais. Políticas Extrafiscais. Desoneração Fiscal. Igualdade Material. Dignidade Humana.

\section{SOCIAL RIGHTS AND EXTRAFISCAL PUBLIC POLICIES: FISCAL EXEMPTION AS AN INSTRUMENT FOR EFFECTIVENESS OF MATERIAL EQUALITY AND PROTECTION TO HUMAN DIGNITY}

\begin{abstract}
This article aims to analyze the importance of the realization of social rights for the realization of material equality and the role of extra-fiscal public policies, in terms of tax relief, for the realization of such rights. It will also be analyzed whether taxation in Brazil has been used to promote the State and Social Welfare, with the fulfillment of Social Rights or if it is merely collection. For this, it was used the critical methods, bibliographic review and document analysis to achieve these objectives.
\end{abstract}

Keywords: Social rights. Extra-Fiscal Policies. Tax Exemption. Material Equality. Human dignity.

\section{INTRODUÇÃO}

O presente artigo visa analisar a importância da realização de políticas públicas extrafiscais para a concretização dos direitos sociais por meio da efetivação da igualdade material, visando à máxima proteção à dignidade humana. Questiona-se, como problemática,

\footnotetext{
${ }^{*}$ Mestre em Direitos Sociais, Difusos e Coletivos. Professor de Direito Constitucional, Financeiro e Tributário na Universidade Estácio de Sá - UNESA/RJ. Pesquisador bolsista do Programa Pesquisa Produtividade da UNESA/RJ. E-mail: darlan_moulin@ @otmail.com
}

Rev. de Direito Sociais e Políticas Públicas | e-ISSN: 2525-9881 | Evento Virtual | v. 6 | n. 1 | 
se a tributação no Brasil é utilizada visando à efetivação dos direitos fundamentais sociais (extrafiscalidade) ou se ela é utilizada apenas para arrecadar recursos para que o Poder Público possa utilizá-los (fiscalidade).

Cogita-se que a extrafiscalidade é um valioso instrumento à disposição do Estado para a concretização dos direitos fundamentais sociais, hipótese esta confirmada por meio de diversos estudos realizados, os quais demonstraram que as políticas públicas extrafiscais, em seu viés de desoneração fiscal, retira ou diminui à carga tributária incidente sobre tais direitos, possibilitando que as pessoas possam gozar desses direitos, efetivando, assim, a igualdade social.

Por tais razões, o presente artigo objetiva demonstrar a importância da concretização dos direitos sociais para a efetivação da igualdade material e o papel das políticas públicas extrafiscais, em seu viés de desoneração fiscal, para a concretização de tais direitos.

Para isso, em um primeiro momento, serão analisados os direitos sociais e a cláusula da reserva do possível como o principal argumento do Poder Público para a não efetivação de tais direitos. Em seguida, será analisada a extrafiscalidade como valioso instrumento a disposição do Estado para a concretização dos direitos sociais e efetivação da igualdade material.

Para tanto, utilizou-se os métodos crítico de revisão bibliográfica e análise de documentos para demonstrar como as políticas extrafiscais são necessárias para a proteção da dignidade humana e tal proteção se dará por meio da concretização dos direitos sociais com a consequente efetivação da igualdade material.

\section{BREVES CONSIDERAÇÕES SOBRE OS DIREITOS FUNDAMENTAIS SOCIAIS E A CLÁUSULA DA RESERVA DO POSSÍVEL}

Inicialmente, cumpre esclarecer que os direitos sociais, também conhecidos como direitos econômicos, sociais e culturais, compõem a segunda dimensão dos direitos humanos e fundamentais e podem ser compreendidos como as "[...] liberdades públicas que tutelam os menos favorecidos, proporcionando-lhes condições de vida mais decentes e condignas com o primado da igualdade real”. (BULLOS, 2010, p. 783). São direitos que buscam garantir a igualdade de condições entre os indivíduos, visando resguardar a dignidade humana para todas as pessoas, especialmente os menos favorecidos socioeconomicamente. 
A necessidade pelo reconhecimento jurídico dos direitos sociais passou a ser fortemente reivindicada a partir do desenvolvimento industrial do século XIX. Nesse período, havia grande exploração de mão de obra, inclusive com trabalhos análogos à escravidão para enriquecer os donos de capital, o que acarretou fortes e diversos questionamentos sobre a justiça das inúmeras liberdades públicas em face de um novo contexto social (SERVEGNINI; OLIVEIRA, 2011, p. 219).

Devido ao estado de grande miséria e péssima qualidade de vida sob a ótica social, foi de fundamental importância o reconhecimento de direitos que pudessem diminuir esses problemas sociais e, ao mesmo tempo, permitir ao sistema capitalista o seu devido funcionamento. Cumpre esclarecer que o desenvolvimento dos direitos sociais não era importante apenas para os menos favorecidos e a classe operária, mas, principalmente, para os detentores do capital, uma vez que o modelo socialista poderia acarretar sérios prejuízos ao capitalismo em redor do mundo (MASSARUTTI; BELMONTE, 2016, p. 176).

Desta forma, verifica-se que a ordem social começou a ganhar força quando começou a ser regulamentada nas Constituições dos Estados Soberanos, tendo sido iniciada pela Constituição mexicana de 1917. No Brasil, a primeira Constituição a regular a ordem econômica e social foi a de 1934, sob o influxo da Constituição alemã de Weimar, permanecendo a ser regulada nas Constituições seguintes (SILVA, 2014, p. 287).

No Brasil, os direitos sociais foram incluídos em um Capítulo próprio referente aos direitos sociais, deixando de integrar o capítulo que tratava da ordem econômica, mas a relação entre os direitos sociais e a ordem econômica e social permanece, já que tais direitos integram o conteúdo da ordem social, conforme disposto no artigo $6^{\circ}$ da Constituição Federal de 1988 que afirma que são direitos sociais a educação, a saúde, a alimentação, o trabalho, a moradia, o transporte, o lazer, a segurança, a previdência social, a proteção à maternidade e à infância e a assistência aos desamparados (SILVA, 2014, p. 287).

Por tais razões, é possível afirmar que os direitos sociais integram os direitos fundamentais do homem, os quais exigem que o Estado promova prestações positivas que estão previstas nos Textos Constitucionais e tem por objetivo viabilizar melhores condições de vida aos menos favorecidos. Esses direitos estão relacionados com a concretização da igualdade material nas relações sociais desiguais, motivo pelo qual estão diretamente ligados ao direito de igualdade. Vale ressaltar que os direitos sociais auxiliam na efetivação dos direitos individuais, visto que possibilitam meios materiais mais eficazes para se alcançar a 
igualdade material ou real, gerando condições mais eficazes com o uso concreto da liberdade (SILVA, 2014, p. 288-289).

Esses direitos não estão relacionados apenas com a garantia da liberdade das pessoas. Eles se projetam para além da preocupação com a intervenção do Estado, visando alcançar “um patamar mais evoluído". (ARAÚJO; NUNES JUNIOR, 2009, p. 93). Os direitos sociais têm por objetivo a proteção à dignidade das pessoas e a concretização da igualdade material, a fim de garantir a concretização da dignidade humana.

Nesse sentido, pode-se dizer que os direitos sociais mais básicos surgiram com os processos de reivindicações que foram gerados na esfera dos movimentos sociais que buscavam a dignidade de cada indivíduo, o qual deveria ser considerado particularmente (SARLET, 2015, p. 222).

É importante esclarecer que apesar desses direitos terem cunho social, eles são resguardados e individualizados como direitos públicos subjetivos, tendo em vista que "a exemplo dos direitos de primeira dimensão, também os direitos sociais (tomados no sentido amplo ora referido) se reportam à pessoa individual, não podendo ser confundidos com os direitos coletivos e/ou difusos da terceira dimensão". (SARLET, 2015, p. 48).

André Ramos Tavares (2018, p. 951) afirma que os direitos sociais são aqueles "que visam a oferecer meios materiais imprescindíveis à efetivação dos direitos individuais". Validando este entendimento, pode-se afirmar que os direitos sociais podem ser definidos como as "prestações positivas proporcionadas pelo Estado direta ou indiretamente, enunciadas em normas constitucionais, que possibilitam melhores condições de vida aos mais fracos, direitos que tendem a realizar a igualização de situações sociais desiguais". (SILVA, 2014, p. 289-290).

Vale ressaltar que foi por meio dos direitos sociais que as pessoas passaram a ter condições de vida mais digna, uma vez que "tornam-se deveres do Estado o assistir à velhice, aos desempregados, à infância, aos doentes, aos deficientes de toda sorte etc." (BASTOS, 2002, p. 436), visto que a positivação de tais direitos nas Constituições impõe aos Estados que realizem verdadeiras prestações positivas visando o desenvolvimento pleno da personalidade humana, principalmente para aqueles que possuem limitações materiais para alcançá-lo.

Desta forma, verifica-se que os direitos sociais buscam dar condições para que as pessoas tenham uma vida digna, tendo em vista a sua positivação constitucional que permite às pessoas que passem a exigir do Estado a concretização desses direitos, o qual está obrigado 
a planejar, criar e desenvolver políticas públicas voltadas para a efetivação desses direitos, garantindo as mínimas condições para uma vida digna, bem como a diminuição das desigualdades sociais, já que "os direitos sociais podem ser considerados uma densificação do princípio da justiça social". (SARLET, 2015, p. 48).

Percebe-se, então, que os direitos fundamentais sociais não são direitos contra o Estado, mas sim por meio do Estado, uma vez que eles obrigam o Poder Público a efetivar determinadas prestações materiais, por meio de normas, como por exemplo, a educação, a saúde, a moradia, e proporcionando a concretização dos direitos constitucionalmente protegidos (SARLET, 2015, p. 27).

No entanto, verifica-se que a Constituição Federal do Brasil de 1988 não garantiu, expressamente, que os indivíduos têm direito de exigir do Estado, de forma administrativa ou judicial, coercitivamente, a concretização dos direitos fundamentais sociais de segunda dimensão. Logo, é imperioso salientar que:

\begin{abstract}
Diante da ausência de previsão do direito de exigir a efetivação de determinados direitos, poderia se pensar que ele não existe, mas, na verdade, as normas inseridas na Constituição possuem um mandamento, uma prescrição, uma ordem com força jurídica e não somente moral. Por isso, se descumprida o sujeito de direito poderá forçar a sua efetivação, inclusive, com a disponibilização de sanções. (MASSARUTTI; BELMONTE, 2016, p. 181).
\end{abstract}

Desta forma, verifica-se que apesar de não haver previsão do direito de exigir a concretização dos direitos fundamentais sociais, as próprias normas constitucionais traduzem um caráter imperativo quanto à efetividade desses direitos, os quais se não forem cumpridos poderão acarretar sanções aos que tinham a obrigação de efetivá-los.

É importante deixar claro que:

Percebe-se, assim, que admitir a imperatividade das normas que preveem direitos sociais e continuar considerando-as como meros programas, não basta para assegurar o direito de exigir do Estado a concretização daqueles direitos, uma vez que pouca força é atribuída aos mesmos quando se trabalha com esta ideia. Nesse sentido, as normas-princípio, atuando como mandamentos de otimização, determinam que algo seja realizado em sua maior capacidade possível; o teor do direito é o máximo diante das possibilidades jurídicas e fáticas, a exemplo das situações financeiramente possíveis perante a necessidade de concretização de outros direitos igualmente fundamentais. (MASSARUTTI; BELMONTE, 2016, p. 181).

Os direitos sociais são considerados mandamentos de otimização, tendo em vista sua condição de princípio que possui a sua máxima prima facie, razão pela qual exigem que as políticas públicas para a sua efetivação, sejam realizadas da melhor forma possível (QUEIROZ, 2011, p. 69). 
É importante esclarecer que o parágrafo primeiro do artigo $5^{\circ}$ da Constituição Federal de 1988, dispõe que os dispositivos constitucionais que tratam dos direitos fundamentais têm aplicação imediata, ainda que não haja lei regulamentadora. Seu conteúdo não necessita de lei para ser efetivado e ainda que haja uma norma do legislativo, não incluirá nada de indispensável ao seu conteúdo, sendo certo que esta lei irá proporcionar maior segurança jurídica quantos aos meios para o seu exercício, bem como as demarcações diante de outros direitos (MOULIN, 2018).

Assim, verifica-se que as normas de direitos sociais possuem o atributo da imperatividade e estão vinculadas à teoria dos princípios, o que possibilita a sua exigência à primeira vista, independentemente de políticas públicas. No entanto, percebe-se a dificuldade de se atribuir exigibilidade aos direitos sociais, exceto nos casos em que a discussão recaia sobre a proteção das condições mínimas para uma existência digna, uma vez que há direitos subjetivos definitivos originários às prestações que servem ao mínimo existencial e o que ultrapassar esse mínimo seria apenas um direito subjetivo prima facie (MASSARUTTI; BELMONTE, 2016, p. 181-182). A doutrina afirma que os direitos sociais devem ser analisados sob o enfoque objetivo e subjetivo.

Pode-se verificar, então, que o enfoque objetivo dos direitos fundamentais sociais está relacionado com a chamada "eficácia dirigente" que estes direitos têm em relação aos órgãos do Estado. Desta forma, o enfoque objetivo pode ser compreendido como uma ordem que é dada ao Estado afirmando que a ele compete a obrigação de buscar a efetivação dos direitos fundamentais sociais, sendo considerados como diretrizes a serem seguidas pelo Estado no momento da aplicação e interpretação do direito infraconstitucional (LEAL; TRINDADE, 2017, p. 383).

De acordo com José Joaquim Gomes Canotilho (2008), os dispositivos constitucionais que disciplinam os direitos sociais possuem características que envolvem a dimensão objetiva com imposições legiferantes que obrigam o legislador a atuar de forma positiva na criação das condições materiais e institucionais, para que as pessoas possam exercer esses direitos mediante a distribuição das referidas prestações positivas aos indivíduos, as quais são densificadoras da dimensão subjetiva essencial desses direitos e auxiliam no cumprimento das imposições institucionais.

Vale ressaltar que além da dimensão objetiva, os direitos sociais devem ser encarados como autênticos direitos subjetivos do indivíduo, estando diretamente relacionados 
à dignidade do ser humano. Assim, os direitos sociais possuem a mesma importância dos direitos, liberdades e garantias, razão pela qual nem o Estado, nem qualquer outra pessoa poderão ofender as posições jurídicas relacionadas com os direitos fundamentais sociais (CANOTILHO, 2008).

Essa dimensão subjetiva reflete a problemática do direito ao reconhecimento a essas prestações sociais na ótica do titular desses direitos, bem como traz a discussão quanto aos próprios limites do Estado, já que os direitos fundamentais sociais são de cunho prestacional e exigem uma atuação positiva do Estado. Desta forma, questiona-se qual o limite de atuação do Estado quanto à concretização do ideal de justiça social, bem como o quantum destas prestações podem ou não ser exigidas, judicialmente, pelos particulares (LEAL; TRINDADE, 2017, p. 383).

Esse problema pode ter muitas razões, dentre as quais podem ser citadas a ausência de densidade normativa suficiente e a necessidade de atuação do legislador até a ausência de recursos financeiros ou limitações orçamentárias, além de o fato dos direitos fundamentais sociais dependerem, para sua efetivação, de decisões políticas sobre quais políticas públicas devem ser utilizadas, não podendo sofrera interferência do Poder Judiciário, salvo para proteger o núcleo essencial dos direitos sociais, sob pena de violação da independência dos Poderes. Por outro lado, é importante frisar que os direitos fundamentais sociais não podem ser compreendidos apenas como meras promessas do constituinte, meros conselhos ou apelos a instâncias políticas sem nenhuma vinculação jurídica própria (DUARTE, 2008, p. 46).

Essa ausência de recursos financeiros e orçamentários é denominada pela doutrina como cláusula da reserva do possível. Ana Paula de Barcellos (2008, p. 236) afirma que:

\begin{abstract}
A expressão reserva do possível procura identificar o fenômeno econômico da limitação dos recursos disponíveis diante das necessidades quase sempre infinitas a serem por eles supridas. [...] a reserva do possível significa que, para além das discussões jurídicas sobre o que se pode exigir judicialmente do Estado - e em última análise da sociedade, já que esta que o sustenta [...].
\end{abstract}

A cláusula da reserva do possível é bastante utilizada pela Administração Pública para justificar a não implementação de políticas públicas eficazes, na concretização dos direitos fundamentais sociais. Esse argumento estatal se baseia no fato de os recursos públicos serem finitos, enquanto que as demandas sociais por tais direitos crescem a cada dia, motivo pelo qual o Estado afirma que há necessidade dessas demandas serem compatibilizadas com as políticas públicas escolhidas pelo Estado, por meio do orçamento público. 
Ada Pellegrine Grinover (2011, p. 138) sustenta que "a implementação de uma política pública depende, em primeiro lugar, de disponibilidade financeira - a chamada reserva do possível. E a justificativa mais usual da administração para a omissão reside exatamente no argumento de que inexistem verbas para implementá-la”.

Quanto a este problema, José Joaquim Gomes Canotilho (2008) defende a concretização dos direitos fundamentais sociais afirmando que:

O entendimento dos direitos sociais, econômicos e culturais como direitos originários implica, como já foi salientado, uma mudança na função dos direitos fundamentais e põe com acuidade o problema da sua efectivação. Não obstante se falar aqui da efectivação dentro de uma 'reserva do possível', para significar a dependência dos direitos econômicos, sociais e culturais não se reduz a um simples 'apelo' ao legislador. Existe uma verdadeira imposição constitucional, legitimadora, entre outras coisas, de transformações econômicas e sociais na medida em que estas forem necessárias para a efectivação desses direitos (cfr. Artigos $2^{\circ}, 9^{\circ} / \mathrm{d}, 80^{\circ}, 81^{\circ}$ ). [...] Por outro lado, a inércia do Estado quanto à criação de condições de efetivação pode dar lugar a inconstitucionalidade por omissão (art. 283. ${ }^{\circ}$ ), considerando-se que as normas constitucionais consagradoras de direitos econômicos, sociais e culturais implicam a inconstitucionalidade das normas legais que não desenvolvem a realização do direito fundamental ou a realizam diminuído a efectivação legal anteriormente atingida.

Cumpre esclarecer que os direitos fundamentais sociais dentro dessa dimensão objetiva devem ser compreendidos como um sistema de valores ou uma ordem objetiva fundamental que servir para a orientação de todo o Estado e a ordem jurídica interna como um todo, bem como devem ser compreendidos como uma mais valia jurídica, transbordando o reconhecimento dos efeitos jurídicos autônomos e indo além da dimensão subjetiva dos direitos fundamentais sociais (DUARTE, 2008, p. 50).

Vale ressaltar que a ausência real de recursos financeiros e orçamentários pelo Estado para efetivar determinado direito fundamental social, não resulta na extinção desse direito, mas simplesmente demonstra o descumprimento do Estado em cumprir um dever constitucional que a ele foi imposto. Além disso, é importante lembrar que embora as atuais condições financeiras não sejam favoráveis elas podem melhorar a qualquer momento, devendo o Estado empreender todos os esforços necessários para que as políticas públicas de efetivação dos direitos sociais se tornem cada vez mais eficientes. Nesse sentido, verifica-se que

[...] o intérprete e o aplicador do direito não devem se preocupar com a figura da reserva do possível, e sim com a determinação rigorosa da área de proteção de cada direito. A pergunta crucial é saber o que exatamente garante a Constituição ao titular de certo direito fundamental prestacional ou social. Isso se relaciona com a baixa densidade normativa dos direitos sociais que atribuem ao legislador um amplo poder de concretização. Assim, por exemplo, a garantia genérica do direito à saúde não 
significa a obrigação estatal de oferecer tudo aquilo que deseja o interessado ou recomendam seus médicos. Tendo estabelecido a área de proteção do direito de maneira rigorosa, cabe ao Estado realizar a prestação, sendo as alegações de 'impossibilidade' irrelevantes, tal como é irrelevante a alegação do contribuinte de que se encontra na impossibilidade de pagar seus impostos. A alegação de impossibilidade de cumprimento do dever estatal pode ter relevância jurídica no momento da execução judicial de condenações à prestação pelo Estado de um direito social, tendo em vista a ordem de cumprimento das prestações em face de critérios orçamentários. Mas nesse caso temos um clássico problema de tratamento desigual de titulares de direitos fundamentais, e não uma justificativa da reserva do possível como forma de relativizar a aplicação imediata dos direitos sociais. (DIMOULIS; MARTINS, 2014, p. 101).

Além disso, é importante frisar que o próprio Poder Judiciário já se manifestou favoravelmente no sentido de que a cláusula da reserva do possível não pode ser utilizada para impedir a concretização dos direitos fundamentais sociais, uma vez que:

Até mesmo o Supremo Tribunal Federal brasileiro já se manifestou a respeito do
argumento da cláusula da reserva do possível, normalmente utilizado pelo Estado,
por meio da análise de um Agravo em Recurso Extraordinário, no qual, apesar de
considerar que a concretização dos direitos econômicos, sociais e culturais depende,
necessariamente, da questão financeira atrelada às possibilidades orçamentárias do
Estado, afirma-se que há necessidade de comprovação a respeito da ausência de
recursos financeiros. Afirma-se também, na mesma decisão colegiada, que não é
lícito ao Estado estabelecer barreiras artificiais que demonstrem, a partir de sua má
gestão financeira e político-administrativa, o ilegítimo, arbitrário e censurável fim de
fraudar e impedir a concretização e manutenção, em benefícios dos indivíduos, de
condições materiais mínimas de existência. Percebe-se, assim, que a posição do
Supremo Tribunal Federal, caminha no sentido de admitir que mesmo diante
da cláusula da reserva do possível, as condiçães mínimas existenciais somente
poderiam ser obstadas se houvessem provas de que o Estado realmente não
possui condições financeiras de arcar com determinadas prestações materiais.
Por outro lado, mesmo que o Estado demonstrasse a ausência de recursos
financeiros, o Poder Público poderia, com o fim de melhorar a qualidade do
atendimento das demandas sociais, amparadas pela Constituição Federal
brasileira, não somente aumentar impostos para atingir esse fim, mas também
poderia readequar a alocaçãa de recursos ou até mesmo, como defendem
alguns, alterar a Constituç̧ão na parte que prevê a vinculação de verbas
públicas, em saúde e educação, por exemplo, para fixar outros percentuais mais
favoráveis a esses direitos fundamentais sociais. (MASSARUTTI; BELMONTE,
2016, p. 183, grifo nosso).

Desta forma, verifica-se que a mera alegação de ausência de recursos financeiros não é suficiente para legitimar o Estado a não efetivar os direitos fundamentais sociais. Além do que, as condições mínimas devem ser observadas e resguardadas, já que estão intimamente ligadas ao princípio da dignidade humana.

Observa-se que a concretização dos direitos fundamentais sociais deve ser o objetivo do Estado, uma vez que tais direitos efetivam a igualdade material. Para tanto, deve o Estado se utilizar dos mecanismos necessários para concretizar tais direitos, inclusive a 
extrafiscalidade tributária, uma vez que essa função permite desonerar a carga tributária, valando-se do interesse humano na tributação.

Portanto, é importante esclarecer que os direitos fundamentais sociais previstos na Constituição Federal do Brasil de 1988 devem ser concretizados pelo Estado por meio da efetivação de políticas públicas eficazes e da extrafiscalidade tributária, uma vez que são verdadeiras prestações impostas ao Poder Público, visando à promoção do livre desenvolvimento da personalidade, a redução das desigualdades sociais, bem como a preservação da dignidade da pessoa humana.

\section{A EXTRAFISCALIDADE TRIBUTÁRIA COMO INSTRUMENTO DE CONCRETIZAÇÃO DOS DIREITOS FUNDAMENTAIS SOCIAIS}

A extrafiscalidade é usualmente utilizada pelo Estado como instrumento de intervenção no campo social, econômico e cultural, seja por meio do aumento das alíquotas tributárias ou da desoneração fiscal total ou parcial. No entanto, é importante esclarecer que o objetivo a ser alcançado pela tributação não deve ser pura e simplesmente a mera arrecadação de receitas aos cofres públicos, mas sim servir como instrumento para a efetivação dos objetivos previstos na Constituição Federal por meio da concretização dos direitos humanos fundamentais, bem como dos princípios constitucionais.

Nesse sentido, Marciano Buffon (2012, p. 54) argumenta que:

[...] a tributação representa um instrumento potencialmente eficaz à realização indireta dos direitos fundamentais. Cabe lembrar que este trabalho propugna a idéia de que é perfeitamente possível que a tributação sirva à realização dos direitos fundamentais econômicos, sociais e culturais, sem deixar de observar os direitos fundamentais limitadores da ação estatal.

Logo, pode-se verificar que a utilização da extrafiscalidade tributária não exige que os direitos fundamentais dos contribuintes sejam mitigados. Pelo contrário, é por meio dela que tais direitos poderão ser concretizados. Nesse sentido, percebe-se que:

De qualquer modo, os tributos extrafiscais, tanto quanto os fiscais, devem submeterse aos princípios que informam a tributação: igualdade, legalidade, generalidade, proporcionalidade, não-confiscatoriedade etc. Além disso, a medida em que interferem nas condutas das pessoas, precisam encontrar respaldo num valor constitucionalmente consagrado, nunca em concepções ideológicas ou morais, incompatíveis com a liberdade na atuação da vida privada das pessoas, que deve imperar num Estado Democrático como o nosso. (CARRAZZA, 2005, p. 132). 
Portanto, é imprescindível que os direitos fundamentais dos contribuintes sejam observados, direitos estes relacionados com as limitações ao Poder de Tributar do Estado, previstos no artigo 150, da Constituição Federal.

Regina Helena Costa (2014, p. 568) esclarece que a tributação deve estar relacionada com a efetivação dos direitos fundamentais. A citada autora sustenta que:

De fato, universalmente vem afirrmando-se uma visão humanista da tributação, a
destacar que essa atividade estatal não busca apenas gerar recursos para o custeio de
serviços públicos, mas, igualmente, o asseguramento do exercício de direitos
públicos subjetivos. Assim é que a tributação constitui instrumento para atingir
os objetivos fundamentais da República Federativa do Brasil, consubstanciados
na construção de uma sociedade livre, justa e solidária; na garantia do
desenvolvimento nacional; na erradicação da pobreza e da marginalização e na
redução das desigualdades sociais e regionais; bem como na promoção do bem
de todos, sem preconceitos de origem, raça, sexo, cor, idade e quaisquer outras
formas de discriminação (art. $3^{\circ}$, I a IV). (Grifo nosso).

É importante esclarecer que esse interesse humano na tributação teve início com a instituição de contribuições sociais, cujo produto da arrecadação deveria ser empregado para a implementação de políticas públicas, na área social. Essas contribuições surgiram quando o Estado passou a exercer uma atividade que não era tipicamente estatal, o que acarretou um aumento nas despesas públicas e, consequentemente, a necessidade de se criar novas fontes de custeio. Ampliando esse entendimento, Claudio Carneiro afirma que:

[...] a partir do momento que o Estado Social de Direito passou a desenvolver, no final do século XIX, uma atividade que não era tipicamente estatal, assumiu um papel que antes não existia. Começou então a investir em assistência social, saúde, previdência (seguridade necessário a obtenção social), educação, etc. Ocorre que, para desempenhar tal papel, fez-se de novas fontes de recursos, ou seja, das contribuiçõos parafiscais. (2012, p. 320-321).

Percebe-se, então, que a política tributária deve ser utilizada pelo Estado de modo a satisfazer a efetivação dos objetivos constitucionais previstos no artigo $3^{\circ}$ da Lei Maior, que é a erradicação da pobreza e da marginalização e a redução das desigualdades sociais e regionais. Para tanto, faz-se necessário que a extrafiscalidade seja empregada de modo a cumprir as determinações previstas no Texto Constitucional. Nesse sentido, Marciano Buffon (2010, p. 570) argumenta que:

Nesse contexto, portanto, emerge a extrafiscalidade para fins de realização dos direitos fundamentais. Não se trata, por óbvio, de algo inédito, pois há muito tempo a extrafiscalidade vem sendo utilizada com vistas à realização de direitos fundamentais, notadamente mediante a concessão de benefícios e incentivos fiscais. O que se advoga neste trabalho é a ampliação do uso da tributação como meio direcionador de comportamentos potencialmente úteis à realização dos direitos fundamentais. Isto é, o sistema tributário deve ser moldado, levando-se em consideração o interesse humano, para que a tributação passe a existir em função do ser humano, e não vice-versa.

Rev. de Direito Sociais e Políticas Públicas | e-ISSN: 2525-9881 | Evento Virtual | v. 6 | n. 1 | 
Darlan Alves Moulin e Yasmin Arbex (2018, p. 293) sustentam que a extrafiscalidade tributária “[...] possui grande importância para a concretização do Estado de Bem-Estar Social, uma vez que é por meio dela que os objetivos constitucionais serão alcançados. Por tais razões, pode-se afirmar que o tributo é um instrumento de concretização dos direitos fundamentais".

Desta forma, é imperioso salientar que a extrafiscalidade deve ser utilizada para garantir a máxima efetividade dos direitos fundamentais, ainda que, aparentemente, ocorra uma quebra na neutralidade econômica do sistema tributário, já que não é o interesse econômico que deve prevalecer, mas sim o interesse voltado para a concretização dos direitos fundamentais. Nesse sentido, observa-se que:

Há muito se reconhece que o sistema tributário tem de levar em consideração a moralidade política ou justiça. Todo aquele que defende um sistema tributário que seja simplesmente 'o melhor para o crescimento econômico' ou 'o mais eficiente' tem de fornecer não somente uma explicação de por que o sistema de sua predileção tem essas virtudes, mas também um argumento de moralidade política que justifique a busca do crescimento ou da eficiência sem que se levem em conta outros valores sociais. (MURPHY; NAGEL, 2005, p. 16).

É importante esclarecer que há uma necessidade de se reduzir a complexidade do sistema tributário, devido as diversas instrumentalidades a serem observadas, o que acaba por dificultar que esse sistema seja útil para a promoção dos objetivos constitucionalmente previstos. Essa redução da complexidade não pode ser compreendida, simplesmente, pela instituição de um imposto único, pois este poderia causar uma grande injustiça fiscal, além de ofender diretamente o princípio da capacidade contributiva. Marciano Buffon (2012, p. 59) sustenta que:

Ratifica-se, então, a impraticabilidade e a própria inconstitucionalidade da hipótese
da existência de um imposto único, seja qual for sua base de incidência, mesmo
porque, se é muito difícil corrigir as imperfeições existentes em cada tributo,
certamente seria impossível conviver com a soma de todas elas, concentradas no
denominado 'imposto único'. Sobretudo, seria inviável conviver com o insanável
vício da injustiça fiscal, decorrente da afronta direta ao princípio da capacidade
contributiva. Outrossim, se reprova que, em nome da simplificação, rejeite-se a
extrafiscalidade e, com isso, sejam negadas as concretas possibilidades de que,
através da tributação, se possa dar uma eficácia social maior aos direitos
fundamentais sociais, econômicos e culturais. Se um sistema tributário de reduzida
complexidade é entendido como incompatível com o mecanismo da extrafiscalidade,
por que optar pela simplificação em detrimento e com o sacrifício da realização dos
direitos fundamentais?

Essa complexidade do sistema tributário está diretamente relacionada à atual realidade socioeconômica, razão pela qual qualquer modelo de tributação que vise concretizar a justiça fiscal será classificado como complexo. A alternativa, pois, que o Estado deve 
buscar, sem sacrificar outros objetivos desse sistema, é a concretização, ainda que indireta, dos direitos fundamentais diretamente relacionados com a dignidade humana, visto que:

[...] a tributação deve ir além da mera arrecadação. Ela deve ter por fundamento a efetivação do Estado de Bem-Estar Social, com a concretização dos direitos fundamentais, principalmente os de cunho social. A extrafiscalidade deve ser utilizada pelo Estado para condicionar o comportamento das pessoas, com o principal objetivo de trazer o bem-estar social. (MOULIN; ARBEX, 2018, p. 294).

Para atingir tais objetivos, o Estado deve se utilizar da extrafiscalidade, pois ela possui uma função de extrema importância na efetivação do interesse humano por meio da tributação. Nesse sentido, Marciano Buffon (2010, p. 572) esclarece que:

Uma vez pensada a tributação a partir do interesse humano, não parece difícil
encontrar os meios com os quais se poderá garantir que, indiretamente, seu formato
privilegie os direitos fundamentais. É certo também que não se pode mergulhar no
fosso da ingenuidade, mediante a adoção da crença de que a tributação tenha
condições de realizar todos os direitos sociais, econômicos e culturais
constitucionalmente previstos. De um lado, a generosa quantidade destes inviabiliza
a concretização efetiva de todos e, de outro lado, as possibilidades da
extrafiscalidade em defesa do interesse humano estão submetidas a evidentes
limitações. Por isso, há de se pensar, num primeiro momento, na introdução do
interesse humano via extrafiscalidade, adotando-se, como critério de escolha, a
materialização dos direitos sociais, econômicos e culturais que estejam mais
intimamente ligados ao princípio da dignidade da pessoa humana. Pode-se dizer,
com todo risco que qualquer escolha desse tipo represente que saúde, educação,
trabalho, moradia e assistência social ocupam um espaço de privilegiada
importância em um rol dessa natureza.

Elucidando esse entendimento, Darlan Alves Moulin e Daisy Rafaela da Silva (2017, p. 231) argumentam que:

[...] é necessário que o sistema tributário brasileiro observe a capacidade de cada contribuinte em pagar os tributos, os quais devem ser utilizados pelo Poder Público dentro da função extrafiscal, pois é através dela que o Estado poderá utilizar a tributação como instrumento de redução das desigualdades sociais e concretização dos direitos sociais.

É importante esclarecer que nem todos os direitos fundamentais previstos na Constituição Federal de 1988 possuem idêntica densidade normativa, ou seja, nem todos se traduzem em um direito público subjetivo de ação para garantir a sua concretização. No entanto, impende ressaltar que isso não isenta o Poder Público do seu dever constitucional de promover políticas públicas, inclusive aquelas relacionadas com a tributação, no sentido de viabilizar que todos os direitos fundamentais possam ter sua eficácia máxima. Por tais razões, mostra-se imprescindível que os direitos fundamentais diretamente relacionados com a dignidade humana não sejam violentados pela tributação (BUFFON, 2012, p. 61).

Portanto, não se pode admitir que a tributação seja utilizada como instrumento para a violação dos direitos humanos fundamentais necessários à existência digna dos indivíduos. 
Dentre esses direitos, pode-se citar o direito fundamental ao trabalho, que é indispensável para a existência digna das pessoas, pois ninguém gostaria de passar a vida inteira vivendo de esmolas e da mínima ajuda assistencial do Estado. O trabalho dignifica o homem e o faz se sentir membro de uma sociedade.

Não é justo permitir que a carga tributária ofenda o direito humano fundamental ao trabalho e seja considera uma das causas impedem a sua efetiva concretização. Nesse sentido, Marciano Buffon (2010, p. 573) reafirma a importância da extrafiscalidade para a concretização dos direitos fundamentais ao afirmar que:

Nesse contexto, o papel da extrafiscalidade parece ser bastante simples e, talvez,
nem possa ser identificado como uma típica política extrafiscal. Impõe-se,
sobremaneira, a necessidade de reduzir a carga tributária incidente sobre o trabalho,
especialmente em relação àqueles setores da economia que ainda se caracterizam
pela utilização intensiva de mão-de-obra. Para sofisticar essa fórmula e privilegiar a
dignidade, essa redução poderia estar condicionada a uma gradativa melhora nas
condições de trabalho, em relação àquelas atividades insalubres e penosas, por
exemplo.

Logo, percebe-se que um dos grandes motivos para a excessiva tributação sobre o trabalho é a problemática do déficit da previdência social, que sempre foi financiada pela arrecadação dos tributos que incidem sobre o trabalho. Assim, para resolver esse problema, é necessário que sejam estudados os reais motivos desse déficit, sejam promovidos os meios necessários para se evitar gastos desnecessários com a previdência social. Além disso, o Estado deve buscar fontes alternativas de custeio para a previdência social, entendendo-se que a tributação sobre o salário acaba ofendendo o conceito constitucional de renda, bem como a própria capacidade contributiva, pois o salário pago à maioria dos brasileiros não consegue nem suprir as suas próprias necessidades básicas (BUFFON, 2010, p. 573).

Marciano Buffon reafirma, ainda, sua posição quanto à utilização da extrafiscalidade tributária como instrumento de concretização dos direitos humanos fundamentais, em especial o direito do trabalho, ao sustentar que:

Existem, enfim, outras inequívocas e expressivas manifestações de capacidade econômica, as quais poderiam ser adequadamente alcançadas pela tributação, com vistas ao custeio da previdência social, possibilitando-se, assim, uma redução expressiva da carga fiscal sobre o trabalho. Isso superaria, em parte, a lógica de que deve prevalecer o interesse econômico, dando-se espaço para que o interesse humano seja o horizonte tributário. (2010, p. 573-574).

Quanto ao direito humano fundamental à saúde, a extrafiscalidade poderia ser utilizada em sua face de desoneração fiscal total ou parcial dos tributos que incidam sobre produtos ou alimentos que auxiliem na manutenção de uma saúde adequada, como os 
medicamentos reconhecidamente essenciais para o bem-estar físico e mental dos indivíduos. Verifica-se, ainda, que a função extrafiscal dos tributos pode ser utilizada na majoração das alíquotas dos tributos quanto a produtos e alimentos que possam causar, comprovadamente, mazelas a boa saúde dos indivíduos (BUFFON, 2012, p. 63).

Nesse sentido, Regina Helena Costa $(2014$, p. 571) atesta que “[...] o direito à saúde deve ser tutelado pela tributação, não cabendo, por exemplo, que os valores referentes às despesas médicas e ao seguro-saúde sejam considerados renda tributável para efeito de Imposto sobre a Renda".

Ainda em relação à concretização do direito humano fundamental à saúde por meio da tributação, o Poder Público deveria possibilitar a dedução integral da base de cálculo do imposto de renda pessoa física das “[...] despesas com medicamentos ou quaisquer produtos que sejam necessários, especialmente porque a não-dedutibilidade implica, concomitantemente, afronta ao princípio da capacidade contributiva". (BUFFON, 2012, p. $63)$.

Carlos Araújo Leonetti afirma que essa não-dedutibilidade é inconstitucional e acaba por ofender diversos princípios constitucionais, dentre eles o da dignidade humana. $\mathrm{O}$ autor sustenta não ser razoável permitir que sejam deduzidas as despesas com médicos e dentistas, por exemplo, e não se aceitar que as despesas com medicamentos também possam ser deduzidas. Nesse sentido, observa-se que:

[...] As despesas com saúde, em tese, não estão sujeitas a limite. Entretanto, os gastos com saúde não incluem a aquisição de medicamentos, exceto se esse valor integrar a conta hospitalar. [...] Com efeito, se o contribuinte pode abater as despesas em que incorreu com médicos, dentistas e outros profissionais de saúde, sem obedecer a limite, uma vez que tais despesas se revelam involuntárias e absolutamente necessárias, não se revela lógico proibir o abatimento de gastos com medicamentos. Ora, tanto as despesas com profissionais de saúde, como as com compra de medicamentos, tem o mesmo fim: a preservação da saúde do contribuinte, e/ou de seus dependentes. (2015, p. 247-248).

Nesse mesmo entendimento, Milena Zampieri Sellmann e Suhel Sarhan Junior (2017, p. 169) sustentam que “[...] é necessário que os gastos realizados para a satisfação dos direitos fundamentais sociais de segunda geração, tais como despesas realizadas com a manutenção da saúde e educação, sejam passíveis de dedução das rendas auferidas".

Os autores (2017, p. 177) argumentam, ainda, que "é dever do Estado oferecer mecanismos para a proteção do direito social à saúde. Assim, também ofende o Princípio da 
Capacidade Contributiva a impossibilidade de desconto das despesas com medicamentos para a manutenção da saúde das rendas tributáveis".

Por se tratar de uma concessão de tratamento diferenciado, a decisão relativa à implementação de determinada política extrafiscal deverá ser tomada por meio de escolhas democráticas, motivo pelo qual se faz necessário o desenvolvimento da cidadania fiscal em todas as pessoas que compõem a sociedade, tendo em vista que a tomada das decisões sobre a carga tributária é de extrema importância (BUFFON, 2012, p. 63).

Quanto ao direito humano fundamental à educação e à cultura, é imperioso destacar que a educação é um direito fundamental social de extrema importância, pois é por meio dela que se pode construir a cidadania e, com isso, concretizar o ideal de democracia, uma vez que “o direito social à educação está diretamente vinculado à dignidade da pessoa humana. [...] $\mathrm{O}$ acesso à educação é uma das formas de realização concreta do ideal democrático". (REMÉDIO; COELHO, 2012, p. 31-32).

Marciano Buffon argumenta sobre a existência de diversas formas de se utilizar da extrafiscalidade para alcançar a concretização de tais direitos. O autor leciona que:

[...] existe uma gama de benefícios e incentivos fiscais a serem concedidos a setores
da economia que investem na formação técnica ou cultural de pessoas, sejam seus
trabalhadores vinculados ao não. Há vários tributos no sistema que podem servir
para tanto, especialmente o imposto de renda e a contribuição social sobre o lucro,
permitindo-se que as despesas suportadas em vista de tais investimentos sejam
consideradas na apuração do lucro tributável, ou sejam deduzidas dos próprios
tributos a pagar. (2012, p. 63-64).

Hugo de Brito Machado sustenta que a limitação de dedução com gastos educacionais padece de inconstitucionalidade, tendo em vista ser a educação direito humano fundamental a todos os indivíduos, não podendo o Estado ofender tal direito por meio da tributação. O referido autor argumenta que:

$1^{\text {a) }}$ É flagrante a inconstitucionalidade do dispositivo legal que limita o direito à dedução dos gastos com educação na determinação da base de cálculo do imposto de renda de pessoa física. $2^{a}$ ) Não se trata de incentivo fiscal, mas de limitação constitucional da competência tributária, fazendo-se com que o imposto incida sobre renda e não sobre despesas. $3^{\text {a }}$ ) Admitir a exclusão ou a limitação do abatimento dos gatos com educação implica, na prática, admitir um imposto sobre os gastos com educação, o que deixa ainda mais evidente o absurdo da limitação questionada. $4^{\mathrm{a}}$ ) Mesmo que se pudesse admitir que o direito à dedução dos gatos com educação na determinação da base de cálculo do imposto de renda constitui incentivo fiscal, ainda assim, em face do que está expresso na Constituição Federal o legislador não poderia excluir ou limitar esse direito sem afrontar a Constituição. (2009, p. 89).

Desta forma, percebe-se que a limitação dos gastos educacionais da base de cálculo do imposto de renda pessoa física (IRPF) ofende, diretamente, a própria dignidade humana, 
tendo em vista ser a educação um direito humano fundamental de extrema importância para o desenvolvimento do próprio Estado Democrático e Social de Direito, motivo pelo qual:

Ao analisar o disposto no artigo $8^{\circ}$, II, b, da Lei $n^{\circ} 9.250 / 95$ pode-se verificar que esta limitação na dedutibilidade das despesas com educação da base de cálculo do IRPF acaba por ocasionar uma inconstitucionalidade, tendo em vista que tal disposição legal não condiz com o espírito de concretização dos direitos fundamentais sociais existentes em nosso Estado Democrático de Direito. (MOULIN, 2017, p. 68).

Esse entendimento é validado por Milena Zampieri Sellmann e Suhel Sarhan Junior (2017, p. 174-175) em:

[...] a educação é direito básico de todos e dever do Estado. Trata-se de um direito fundamental social. Se o sistema não permite o acesso de todos à educação, o Estado tem responsabilidade e o mínimo que se pode permitir é que quem teve gastos com o que deveria ser custeado pelo Estado, tenha o direito ao abatimento dessas despesas, sem limites, da base de cálculo do Imposto sobre a Renda e Proventos de Qualquer Natureza. [...] Os gastos com instrução não geram renda e, por isso, não podem ser tidos como sinais de riqueza. Para a observância da capacidade contributiva, as despesas derivadas destes gastos devem ser deduzidas dos ingressos de valores no patrimônio do contribuinte. Somente assim será possível verificar o efetivo acréscimo patrimonial passível de tributação.

Nesse sentido, Regina Helena Costa (2014, p. 571) leciona que "[...] Tal como ocorre em relação ao direito à saúde, as despesas com a educação, do contribuinte e seus dependentes, não podem integrar a renda tributável, sob pena de violar-se direito fundamental, uma vez constituírem autênticas despesas necessárias à manutenção das pessoas físicas”.

No entanto, os benefícios fiscais a serem concedidos pela extrafiscalidade, em especial aqueles relacionados com a cultura, devem ser concedidos com muito cuidado e zelo, tendo em vista a concessão indiscriminada de recursos públicos que foram utilizados, de forma inadequada, em diversas obras culturais de caráter duvidoso. Ou ainda obras culturais que foram produzidas somente por determinada classe de pessoas que não necessitaria dos recursos públicos para tal fim. Além disso, têm-se a fiscalização deficitária do Poder Público em relação aos recursos concedidos, o que acaba por favorecer a utilização e aplicação indevida de tais recursos (BUFFON, 2010, p. 575).

A extrafiscalidade poderá, ainda, ser utilizada para a máxima proteção do meio ambiente por meio da concessão de incentivos e benefícios fiscais ou da oneração da carga tributária, quando houver ofensa a tal direito. Nesse sentido, percebe-se que:

No campo da proteção ambiental a extrafiscalidade encontra um terreno bastante fértil a sua aplicabilidade, uma vez que poderão ser concedidos benefícios e incentivos fiscais, relativamente àquelas situações, atividades ou produtos ambientalmente corretos e, ao contrário, poderá haver uma oneração quando as 
referidas estiverem na contramão do direito fundamental ao ambiente ecologicamente equilibrado (art. 225 da CF/88). (BUFFON, 2012, p. 64).

Verifica-se que o tributo pode ser utilizado pelo Poder Público para tornar efetivo o direito fundamental ao meio ambiente ecologicamente equilibrado, tendo em vista que a:

Tributação ambiental significa o emprego do tributo como instrumento de defesa e
preservação do meio ambiente. Em verdade, o tributo é instrumento do Estado para
consecução de fins fiscais, mas também pode ter finalidade extrafiscal, mormente
porque o Estado brasileiro tem postura intervencionista. No caso da proteção ao
meio ambiente, a Constituição Federal de 1988 é expressa no sentido de imputar ao
Poder Público o dever de defender e preservar o meio ambiente ecologicamente
equilibrado. Dentro dessa função constitucional conferida ao Estado, haverá, então,
o emprego dos mais diversos instrumentos de intervenção na seara privada para se
conduzir comportamentos ambientalmente desejados e se desestimular
comportamentos ambientalmente indesejados. Dentro dessa ótica, o tributo com viés
ambiental serve de instrumento do Estado para exercer sua função de defesa e
preservação do meio ambiente ecologicamente equilibrado. (PINTO; MENEZES,
2012, p. 208-209).

Regina Helena Costa (2014, p. 571) afirma que a tributação deve ser utilizada para a preservação dos direitos difusos, especialmente em relação ao meio ambiente. Nesse sentido, verifica-se que:

Em matéria ambiental, isso manifesta-se mediante o emprego dos chamados tributos ambientais, isto é, aqueles vocacionados ao atingimento de propósitos voltados à preservação do meio ambiente, bem como mediante a exigência de tributos que, mesmo sem terem sido instituídos com essa finalidade, podem ser utilizados para modular condutas a ela afinadas.

Portanto, conclui-se que a extrafiscalidade é um instrumento válido, do qual o Estado deve se valer para concretizar os direitos fundamentais sociais. É por meio dela que a tributação poderá satisfazer o interesse humano que deve predominar para a implementação de políticas públicas dentro do Estado Democrático e Social de Direito.

\section{CONCLUSÃO}

Por meio do presente estudo, constatou-se que a extrafiscalidade tributária é um valioso instrumento para a concretização dos direitos fundamentais sociais, uma vez que essa política pública tributária sendo utilizada no seu viés de desoneração físcal, retira o peso da tributação sobre tais direitos, possibilitando que as pessoas possam deles usufruir, passando a ter melhores condições de vida. 
Como visto, a efetivação dos direitos sociais permite a realização da igualdade material e faz com que as pessoas se autodeterminem na busca por uma vida digna. No entanto, para que haja a plena concretização desses direitos é preciso que o Poder Público promova políticas públicas eficazes para a proteção daqueles que se encontram em situação de vulnerabilidade social. Além da implementação de tais políticas, é necessário que a carga tributária sobre tais direitos sejam aliviadas, motivo pelo qual torna-se imprescindível o uso da extrafiscalidade tributária, de modo a permitir que as pessoas gozar de tais direitos sem que sofram com o peso da tributação.

Conclui-se, portanto, que a extrafiscalidade tributária (desoneração fiscal) é um valioso instrumento à disposição do Estado para concretizar os direitos sociais e possibilitar a efetivação da igualdade material.

\section{REFERÊNCIAS}

ARAUJO, Luiz Alberto David; NUNES JUNIOR, Vidal Serrano. Curso de Direito Constitucional. São Paulo: Saraiva, 2009.

BARCELOS, Ana Paula de. A eficácia jurídica dos princípios constitucionais: O princípio da dignidade da pessoa humana. 2 ed. amplamente revista e atualizada. Rio de Janeiro: Renovar, 2008.

BUFFON, Marciano. A tributação como instrumento de concretização dos direitos fundamentais. Revista da Faculdade de Direito de Uberlândia. v. 38, n.2, p. 555-579, 2010 .

BUFFON, Marciano. Tributação e Direitos Sociais: A extrafiscalidade como instrumento de efetividade. Revista Brasileira de Direito, v 8, n 2, p. 38-68, jul-dez, 2012.

BULLOS, Uadi Lamêgo. Direito constitucional ao alcance de todos. 2. ed. São Paulo: Saraiva, 2010.

CANOTILHO, José Joaquim Gomes. 'Metodologia fuzzy' e 'camaleões normativos' na problemática atual dos direitos econômicos, sociais e culturais. In: CANOTILHO,José Joaquim Gomes. Estudos sobre direitos fundamentais. 2. ed. Coimbra: Coimbra, 2008. p. 97-113.

CARNEIRO, Claudio. Curso de direito tributário e financeiro. $4^{\mathrm{a}}$ ed. São Paulo: Saraiva, 2012.

CARRAZZA. Roque Antonio. Imposto sobre a renda: perfil constitucional e temas específicos. São Paulo: Malheiros. 2005. 
COSTA, Regina Helena. Tributação e Direitos Fundamentais. In: ANDRIGHI, Nancy (Org.). Doutrina: edição comemorativa, 25 anos. Brasília: Superior Tribunal de Justiça, 2014, p. 561$573 . \quad$ Disponível em: <https://ww2.stj.jus.br/publicacaoinstitucional/index.php/Dout25anos/article/view/70/3811>.

Acesso em 30 abr. 2020.

DIMOULIS, Dimitri; MARTINS, Leonardo. Teoria geral dos direitos fundamentais. $5^{\mathrm{a}}$ ed. São Paulo: Atlas, 2014.

DUARTE, Leonardo de Farias. Obstáculos econômicos a efetivação dos direitos fundamentais sociais. Coimbra: Renovar, 2008.

GRINOVER, Ada Pellegrini.O controle jurisdicional de políticas públicas. In: GRINOVER, Ada Pellegrini; WATANABE, Kazuo (Coords.). O controle jurisdicional de políticas públicas. Rio de Janeiro: Forense, 2011. p. 125-150.

LEAL, Rogério Cesta. TRINDADE, Antonio Cesar. As dimensões da reserva do possível e suas implicações na efetivação dos direitos fundamentais sociais. Disponível em < http://editora.unoesc.edu.br/index.php/uils/article/view/4033 >. Acesso em 29 abr. 2020.

LEONETTI, Carlos Araujo. Os Direitos Humanos da Tributação - um Caso Concreto: o direito à dedução integral dos gastos com medicamentos da base de cálculo do imposto sobre a renda. Sequência (Florianópolis) [online]. 2015, n.70, pp.235-252. ISSN 0101-9562. http://dx.doi.org/10.5007/2177-7055.2015v36n70p235. Disponível em: <http://www.scielo.br/scielo.php?pid=S217770552015000100235\&script=sci_abstract\&tlng=es>. Acesso em 30 abr. 2020.

MACHADO, Hugo de Brito. Gastos com educação e imposto de renda. Revista dialética de direito tributário, São Paulo, n.165, p. 81-89, jun./2009.

MASSARUTTI, Eduardo Augusto de Souza; BELMONTE, Danilo Zanco. Direitos Sociais na Constituição Federal Brasileira: Fundamentais, Subjetivos e Definitivos. In: CONGRESSO NACIONAL DO CONPEDI, 25, 2016, Curitiba/PR, Anais do XXV Congresso Nacional do Conpedi. Florianópolis: Fundação Boiteux. ISBN: 978-85-5505-362-7.

MOULIN, Darlan Alves. Direito humano ao desenvolvimento e extrafiscalidade tributária: instrumentos de concretização dos direitos sociais e de redução das desigualdades. 2018. Dissertação (Mestrado em Direito). Centro Universitário Salesiano de São Paulo, 2018.

MOULIN, Darlan Alves. A inconstitucionalidade do limite de dedução das despesas educacionais no IRPF e a tutela jurisdicional para a Concretização do Direito Fundamental à Educação. Revista Brasileira de Direitos e Garantias Fundamentais. Brasília/DF. v. 3. n. 1. p. 60-79, jan/jun. 2017.

MOULIN, Darlan Alves; SILVA, Daisy Rafaela da. A tributação sobre o consumo e as desigualdades sociais no estado de crise socioeconômica . Revista DIREITO UFMS, Campo Grande, MS, v. 3, n. 1, p. 211-232, jan./jul. 2017. Disponível em: < http://seer.ufms.br/index.php/revdir/article/view/2978>. Acesso em 30 abr. 2020.

Rev. de Direito Sociais e Políticas Públicas | e-ISSN: 2525-9881 | Evento Virtual | v. 6 | n. 1 |

p. 45-65 | Jan/Jun. 2020 
MOULIN, Darlan Alves; ARBEX, Yasmin Juventino Alves. A extrafiscalidade tributária e as políticas públicas como instrumentos de promoção da dignidade humana e de efetivação do Estado de Bem-Estar Social. In: CONGRESSO NACIONAL DO CONPEDI, 27, 2018, Salvador/BA, Anais do XXVII Congresso Nacional do Conpedi. Florianópolis: Fundação Boiteux. ISBN: 978-85-5505-618-5.

MURPHY, Liam; NAGEL, Thomas. O mito da propriedade: os impostos e a justiça. Trad.: Marcelo Brandão Cipolla. São Paulo: Martins Fontes, 2005.

PINTO, Keziah A. V. Silva; MENEZES, Milena Z. S. de. Tributo como instrumento para assegurar o dieito fundamental ao meio ambiente. In: YOSHIDA, C. Y. M; RAMPAZZO, L. (Orgs.). O direito e a dignidade humana: aspectos éticos e socioambientais. Campinas, SP: Alínea, 2012, p. 191-223.

QUEIROZ, Maria do Socorro Azevedo de. Judicialização dos direitos sociais prestacionais: a efetividade pela interdependência dos direitos fundamentais na constituição brasileira. Curitiba: Juruá, 2011.

REMÉDIO, José Antônio; COELHO, Rodrigo Batista. A concretização dos direitos sociais como imperativo da igualdade material: políticas públicas educacionais e tutela coletiva. Direito e Paz. Lorena, Ano XIV, n. 26, p. 09-40, 1. sem. 2012.

SARLET, Ingo Wolfgang. A eficácia dos direitos fundamentais: uma teoria geral dos direitos fundamentais na perspectiva constitucional. 12. ed. rev. atual. eampl. Porto Alegre: Livraria do Advogado, 2015.

SELLMANN, Milena Zampieri; SARHAN JUNIOR, Suhel. Direitos fundamentais de segunda geração e a tributação da renda. In: CONGRESSO NACIONAL DO CONPEDI, 26, 2017, Brasília/DF, Anais do XXVI Congresso Nacional do Conpedi. Florianópolis: CONPEDI, 2017. ISBN: 978-85-5505-446-4.

SERVEGNINI, Angélica Padilha; OLIVEIRA, Melissa Barbieri de. A efetividade dos direitos sociais diante da atual conjuntura econômica: a reserva do possível e o mínimo existencial frente ao direito à moradia e o direito à alimentação. Revista Jurídica do Cesumar: mestrado. Maringá, v. 11, 1.2011 .20 Disponível <http://periodicos.unicesumar.edu.br/index.php/revjuridica/issue/view/95.> Acesso em 29 abr. 2020.

SILVA, José Afonso da. Curso de Direito Constitucional Positivo. 37 ed, São Paulo: Malheiros, 2014. 